\title{
ORIGINAL ARTICLE \\ Does religious coping and spirituality have a moderating role on depression and anxiety in patients with spinal cord injury? A study from Iran
}

\author{
P Rahnama ${ }^{1}$, AN Javidan ${ }^{2}$, H Saberi $^{2}$, A Montazeri $^{3}$, S Tavakkoli ${ }^{4}$, AH Pakpour ${ }^{5}$ and M Hajiaghababaei ${ }^{2}$
}

Objectives: We evaluate the level of anxiety and depression among patients with spinal cord injury (SCI) in relation with their religious coping and spiritual health.

Setting: Brain and Spinal Cord Injury Repair Research Center, Neuroscience Institute, Tehran University of Medical Sciences, Tehran, Iran.

Methods: A sample of patients with $\mathrm{SCl}$ participated in this cross-sectional study. They completed a sociodemographic questionnaire, the Hospital Anxiety and Depression Scale, the Brief Religious Coping Questionnaire and the Spiritual Well-being Scale. Then, the association between anxiety, depression and independent variables was examined.

Results: In all, 213 patients with SCI were studied. Of these, 64 (30\%) have had anxiety and 32 (15\%) have had depression. Multiple logistic regression analyses revealed that gender (odds ratio $(\mathrm{OR})$ for female $=3.34,95 \%$ confidence interval $(\mathrm{Cl})=1.31-8.51$, $P=0.011$ ), employment (OR for unemployed $=5.71,95 \% \mathrm{Cl}=1.17-27.78, P=0.031)$, negative religious coping $(\mathrm{OR}=1.15,95 \%$ $\mathrm{Cl}=1.04-1.28, P=0.006)$ and existential spiritual well-being $(\mathrm{OR}=0.93,95 \% \mathrm{Cl}=0.89-0.97, P=0.003)$ were significant contributing factors to anxiety (Table 3 ), whereas negative religious coping $(\mathrm{OR}=1.21,95 \% \mathrm{Cl}=1.06-1.37, P=0.004)$ and existential spiritual well-being $(\mathrm{OR}=0.90,95 \% \mathrm{Cl}=0.84-0.96, P=0.001)$ were significant contributing factors to depression.

Conclusion: The findings indicated that depression and anxiety are two psychologically important side effects after SCl. The findings also indicated that religion and spiritual well-being have a moderating role on occurrence of depression and anxiety.

Spinal Cord (2015) 53, 870-874; doi:10.1038/sc.2015.102; published online 30 June 2015

\section{INTRODUCTION}

Spinal cord injury (SCI) is a catastrophic condition worldwide. ${ }^{1,2}$ In Tehran, the prevalence of SCI is 4.4 per $100000 .^{3}$ SCI affects a person's physical function including permanent neurological injury, disability, changes to bowel and bladder control, loss of sensation and sexual functioning. ${ }^{4,5}$ In addition, patients with cerebral injury may suffer from depressive or anxiety disorders. ${ }^{6,7}$ It has been shown that occurrence of depression in patients with SCI is associated with several problems such as decrease improvements in rehabilitation, ${ }^{8}$ diminished quality of life ${ }^{9}$ and increased morbidity and mortality. ${ }^{10}$

It is important to determine risk factors associated with depression and anxiety in order to provide interventions to reduce negative outcomes in patients with SCI. A study showed that anxiety and depression were higher in females, well-educated patients and those who reported pain. ${ }^{11}$ In addition, the review of several studies revealed that the religious coping strategy correlated with better recovery from depression and anxiety. There is also evidence that the religious involvement is more common in patients with chronic disease and poor prognosis. ${ }^{12}$

There are two types of coping strategies to physical and psychological adjustment in patients with disabilities including religious and spiritual approaches. ${ }^{13}$ Religiosity is a comprehensive sociological term used to refer to the numerous aspects of religious activity, dedication and belief (religious doctrine), ${ }^{14}$ whereas spirituality is defined as subjective and individualistic experiences and helping one understand and find purpose and meaning in life. Indeed, religiosity and spirituality are considered to be central issues in the process of coping with stressors, especially in patients dealing with chronic illness. ${ }^{15,16}$ However, religious coping is an active process that includes organized and institutionalized religious activities. ${ }^{17-19}$

Islam is the religion of the majority of Iranian population. Although Islamic teachings encourage people to tolerate negative life events, it is argued that people's tolerance highly depends on one's religiosity and spirituality. Therefore, we designed a study to examine the association between various factors including demographic, injury and spirituality and religious coping and the occurrence of anxiety and depression in patients with SCI. It was thought that conducting this study in Iran where most people usually practice religion might add to the existing knowledge on the topic. In addition, we thought the findings might help plan nonpharmaceutical interventions in order to reduce anxiety and depression in patients who suffer from SCI in Iran.

${ }^{1}$ Department of Midwifery, Shahed University, Tehran, Iran; ${ }^{2}$ Brain and Spinal Cord Injury Research Center (BASIR), Neuroscience Institute, Tehran University of Medical Sciences, Tehran, Iran; ${ }^{3}$ Mental Health Research Group, Health Metrics Research Centre, Iranian Institute for Health Sciences Research, ACECR, Tehran, Iran; ${ }^{4}$ Department of Psychology, University of Payam-e-Noor, Tehran, Iran and ${ }^{5}$ Social Determinants of Health Research Center (SDH), Qazvin University of Medical Sciences, Qazvin, Iran Correspondence: M Hajiaghababaei, Brain and Spinal Cord Injury Research Center (BASIR), Neuroscience Institute, Tehran University of Medical Sciences, Imam Hospital, Gharib Street, Keshavarz Boulevard, Tehran 14-19733141, Iran.

E-mail: mnhajbabaei@yahoo.com or m-hajbabaei@farabi.tums.ac.ir

Received 20 January 2015; revised 4 May 2015; accepted 12 May 2015; published online 30 June 2015 


\section{MATERIALS AND METHODS}

\section{Patients and settings}

This was a cross-sectional study carried out in Tehran, Iran. A sample of patients with SCI attending the Brain and Spinal Cord Injury Repair Research Center in Tehran, Iran, a referral center, were entered into the study. The inclusion criteria were as follows: having SCI and at least 18-year old at the time of study. Patients were excluded if they had chronic comorbidity including diabetes mellitus, cardiovascular diseases, hypertension, rheumatic diseases and kidney disease. Demographic and injury-related characteristics were obtained from interviews, neurologic examination and hospital records and self-report. The study was approved by the Institutional Review Board of the Brain and Spinal Cord Injury Research Center in Neuroscience Institute, Tehran University of Medical Sciences, Tehran, Iran.

\section{Measures}

1. A study-specific questionnaire in order to collect data on demographic and injury-related characteristics.

2. International standards for neurological classification of SCI developed by the American Spinal Injury Association (ASIA) in order to classify injury severity into complete (ASIA grade A) and incomplete (ASIA grades B-E) ${ }^{20}$

3. The Brief Religious Coping Questionnaire (RCOPE) to collect data on religious coping. It is a valuable, theoretically based comprehensive tool for measuring religious coping. This is a 14-item questionnaire that consists of two subscales: positive and negative religious coping. Positive religious coping reflects a secure relationship with a transcendent force, and negative religious coping reflects underlying struggles within oneself, with others and with the divine. Each item is rated on a 4-point Likert scale ranging from 1 (strongly disagree) to 4 (strongly agree) giving a total score of 7-28 for each subscale. ${ }^{21}$ The inventory has been validated in the Iranian population. ${ }^{22}$

4. The Spiritual Well-Being Scale (SWBS) to evaluate spiritual well-being. The SWBS is a 20-item questionnaire that consists of two subscales: a religious well-being and an existential well-being. Each item is rated on a 6-point Likert scale (from 1 to 6), giving a total score ranging from 20 to 120 where the higher scores indicate greater well-being. The Religious well-being subscale provides a self-assessment of one's relationship with God, whereas the existential well-being subscale gives a self-assessment of one's sense of life purpose and life satisfaction. ${ }^{23}$ This questionnaire has been used in other studies in Iran. The psychometric properties of the Iranian version of the questionnaire are well documented. ${ }^{24}$

5. The Hospital Anxiety and Depression Scale (HADS) in order to measure anxiety and depression. The HADS consists of 14 questions. Each item is rated on a 4-point Likert scale ranging from 0 (absence of symptoms) to 3 (severe symptoms). Scores on both anxiety and depression subscales range from 0 to 21 . Scores of 11 or more on either subscale are considered to be a significant 'case' of psychological morbidity, whereas scores of 8-10 represent 'borderline' and 0-7 'normal'. The psychometric properties of the Iranian version of HADS are reported elsewhere. ${ }^{25}$

\section{Statistical analysis}

Descriptive statistics were used to explore the data. Logistic regression analysis was performed to identify correlates of anxiety and depression with spirituality and religious coping. Depression and anxiety status were treated as dependent variables, whereas age, gender education, work status, neurological classification of SCI (ASIA grade), time since injury, spiritual well-being and religious coping were considered as independent variables. For the purpose of the logistic regression analysis 'borderline' and 'normal' categories were merged. In order to reduce experimental bias, the main investigator was blind to when the data analysis had been completed.

\section{RESULTS}

In all, 213 patients with SCI were studied. The mean age of participants was 33.7 (s.d. $=9.5$ ) years, and 64 patients $(30 \%)$ reported severe anxiety, whereas only 32 patients (15\%) reported severe depression. Overall, 20 patients (9\%) reported both severe anxiety and depression. The characteristics of the study sample are shown in Table 1. The comparison of spiritual well-being and religious coping by gender, education, marital status and employment is shown in Table 2. There were significant differences between gender and religious well-being and positive religious coping $(P=0.023$ and $P=0.005$, respectively). In addition, there was a significant difference in existential well-being between employed and unemployed patients $(P<0.001)$.

Table 1 The characteristics of study sample $(n=213)$

\begin{tabular}{|c|c|}
\hline & No. (\%) \\
\hline \multicolumn{2}{|l|}{ Age (years) } \\
\hline Mean (s.d.) & $33.71(9.58$ \\
\hline Range & $(19-63)$ \\
\hline \multicolumn{2}{|l|}{ Gender } \\
\hline Male & $165(77.5)$ \\
\hline Female & $48(22.5)$ \\
\hline \multicolumn{2}{|l|}{ Education } \\
\hline Primary & $37(17.4)$ \\
\hline Secondary & $131(61.5)$ \\
\hline Higher & $45(21.1)$ \\
\hline \multicolumn{2}{|l|}{ Married status } \\
\hline Single & 78 (36.6) \\
\hline Married & $113(53.1)$ \\
\hline Divorce & $22(10.3)$ \\
\hline \multicolumn{2}{|l|}{ Employment status } \\
\hline Employed & $30(14.1)$ \\
\hline Unemployed & $183(85.9)$ \\
\hline \multicolumn{2}{|c|}{ Neurological classification of spinal cord injury (ASIA grade) } \\
\hline Incomplete & 99 (46.5) \\
\hline Complete & $114(53.5)$ \\
\hline \multicolumn{2}{|l|}{ Time since injury } \\
\hline Mean (s.d.) & $4.05(5.02)$ \\
\hline Range & $0.08-33.0$ \\
\hline \multicolumn{2}{|l|}{ Anxiety } \\
\hline Caseness & $64(30)$ \\
\hline Borderline & $53(25)$ \\
\hline Normal & $96(45)$ \\
\hline \multicolumn{2}{|l|}{ Depression } \\
\hline Caseness & $32(15)$ \\
\hline Borderline & $62(29)$ \\
\hline Normal & $119(56)$ \\
\hline \multicolumn{2}{|l|}{ Spiritual well-being } \\
\hline Religious well-being & $50.9(9.0)$ \\
\hline Existential well-being & $41.3(10.1)$ \\
\hline \multicolumn{2}{|l|}{ Religious coping } \\
\hline Positive religious coping & $24.22(4.01)$ \\
\hline Negative religious coping & $15.02(3.68)$ \\
\hline
\end{tabular}


Table 2 Comparing spiritual well-being and religious coping by gender, education, marital status and employment $(n=213)$

\begin{tabular}{|c|c|c|c|c|}
\hline & \multicolumn{2}{|c|}{ Spiritual well-being } & \multicolumn{2}{|c|}{ Religious coping } \\
\hline & $\begin{array}{l}\text { Religious } \\
\text { well-being } \\
\text { Mean (s.d.) }\end{array}$ & $\begin{array}{l}\text { Existential } \\
\text { well-being } \\
\text { Mean (s.d.) }\end{array}$ & $\begin{array}{c}\text { Positive } \\
\text { religious coping } \\
\text { Mean (s.d.) }\end{array}$ & $\begin{array}{l}\text { Negative } \\
\text { religious coping } \\
\text { Mean (s.d.) }\end{array}$ \\
\hline \multicolumn{5}{|l|}{ Gender } \\
\hline Female & $50.2(9.45)$ & 40.43 (11.04) & $25.64(2.50)$ & $15.64(3.72)$ \\
\hline Male & $53.2(7.25)$ & $41.61(9.89)$ & $23.80(4.27)$ & $14.84(3.66)$ \\
\hline$P$ & $0.023^{a}$ & $0.482^{\mathrm{a}}$ & $0.005^{a}$ & $0.188^{a}$ \\
\hline \multicolumn{5}{|l|}{ Education } \\
\hline Primary & $51.18(8.56)$ & $40.89(8.52)$ & $24.24(3.86)$ & $15.32(3.71)$ \\
\hline Secondary & $50.68(8.70)$ & $40.71(10.90)$ & $24.10(3.79)$ & $15.27(3.65)$ \\
\hline Higher & $51.37(10.60)$ & $43.55(8.91)$ & $24.53(4.79)$ & $14.06(3.66)$ \\
\hline$P$ & $0.891^{b}$ & $0.259^{b}$ & $0.829^{b}$ & $0.143^{b}$ \\
\hline \multicolumn{5}{|l|}{ Marital status } \\
\hline Single & $50.70(10.03)$ & $41.46(10.08)$ & $23.75(4.75)$ & 15.14 (3.59) \\
\hline Married & $50.55(8.61)$ & $42.04(9.71)$ & 24.45 (3.59) & 14.79 (3.89) \\
\hline Divorced & $53.54(7.65)$ & 37.36 (12.03) & $24.68(3.12)$ & $15.81(3.00)$ \\
\hline P & $0.358^{b}$ & $0.140^{b}$ & $0.429^{b}$ & 0.4670 \\
\hline \multicolumn{5}{|c|}{ Employment status } \\
\hline Employed & $53.36(7.57)$ & $47.20(8.76)$ & $24.56(3.56)$ & $14.33(2.97)$ \\
\hline Unemployed & $50.52(9.25)$ & $40.38(10.06)$ & $24.16(4.09)$ & $15.14(3.78)$ \\
\hline$P$ & $0.111^{\mathrm{a}}$ & $<0.001^{\mathrm{a}}$ & $0.612^{\mathrm{a}}$ & 0.266 \\
\hline
\end{tabular}

aDerived from $t$-test.

${ }^{b}$ Derived from one-way analysis of variance.

\section{Risk factors for anxiety and depression}

The relationship between depression and anxiety with independent variables was examined by performing multiple logistic regressions. The results indicated that gender (odds ratio (OR) for female $=3.34$, $95 \%$ confidence interval $(\mathrm{CI})=1.31-8.51, P=0.011)$, employment (OR for unemployed $=5.71,95 \% \mathrm{CI}=1.17-27.78, \quad P=0.031$ ), negative religious coping $(\mathrm{OR}=1.15,95 \% \mathrm{CI}=1.04-1.28, P=0.006)$ and existential spiritual well-being $(\mathrm{OR}=0.93,95 \% \mathrm{CI}=0.89-0.97$, $P=0.003)$ were significant contributing factors to anxiety (Table 3), whereas negative religious coping $(\mathrm{OR}=1.21,95 \%$ $\mathrm{CI}=1.06-1.37, \quad P=0.004)$ and existential spiritual well-being $(\mathrm{OR}=0.90,95 \% \mathrm{CI}=0.84-0.96, P=0.001)$ were significant contributing factors to depression (Table 4). Indeed, the findings from the present study indicated that female, unemployment, negative religious coping and lower score in existential dimension of spiritual well-being were significant predictors of anxiety. In addition, negative religious coping and lower score in existential dimension of spiritual well-being were significant contributing factors to depression.

\section{DISCUSSION}

The findings from this study showed that the prevalence of severe anxiety among patients with SCI in Iran was relatively high, whereas the prevalence of severe depression was low, even lower compared with the general population. ${ }^{26}$ Perhaps this low level of severe depression might be attributed to the support they were receiving from different organizations and family. A recent meta-analysis of studies on depression in patients with SCI revealed that the prevalence
Table 3 The results obtained from multiple logistic regression analysis indicating risk factors for anxiety $(n=213)$

\begin{tabular}{|c|c|c|c|}
\hline & $O R^{a}$ & $95 \% \mathrm{Cl}$ & $P$ \\
\hline Age (years) & 1.00 & $0.96-1.05$ & 0.734 \\
\hline \multicolumn{4}{|l|}{ Gender } \\
\hline Male & 1.0 (ref.) & & \\
\hline Female & 3.34 & $1.31-8.51$ & 0.011 \\
\hline \multicolumn{4}{|l|}{ Education } \\
\hline Primary & 0.47 & $0.14-1.61$ & 0.232 \\
\hline Secondary & 1.02 & $0.396-2.67$ & 0.953 \\
\hline Higher & 1.0 (ref.) & & \\
\hline \multicolumn{4}{|l|}{ Marital status } \\
\hline Single & 1.0 (ref.) & & \\
\hline Married & 1.70 & $0.66-4.34$ & 0.267 \\
\hline Divorced & 1.60 & $0.39-6.516$ & 0.505 \\
\hline \multicolumn{4}{|l|}{ Employment status } \\
\hline Employed & 1.0 (ref.) & & \\
\hline Unemployed & 5.71 & $1.17-27.78$ & 0.031 \\
\hline \multicolumn{4}{|c|}{ Neurological classification of spinal cord injury (ASIA grade) } \\
\hline Incomplete & 1.01 & $0.48-2.06$ & 0.993 \\
\hline Complete & 1.0 (ref.) & & \\
\hline Time since injury & 0.94 & $0.86-1.02$ & 0.177 \\
\hline \multicolumn{4}{|l|}{ Spiritual well-being } \\
\hline Religious well-being & 1.03 & $0.98-1.08$ & 0.196 \\
\hline Existential well-being & 0.93 & $0.89-0.97$ & 0.003 \\
\hline \multicolumn{4}{|l|}{ Religious coping } \\
\hline Positive religious coping & 0.94 & $0.84-1.04$ & 0.252 \\
\hline Negative religious coping & 1.15 & $1.04-1.28$ & 0.006 \\
\hline
\end{tabular}

Abbreviations: ASIA, American Spinal Injury Association; Cl, confidence interval; OR, odds ratio. aAdjusted for all independent variables using the enter model.

of depression in this population was $22.2 \%{ }^{27}$ However, our findings on severe anxiety were consistent with previous studies where, for instance, it was reported that out of the 443 patients with SCI $30 \%$ experienced anxiety disorders. ${ }^{28}$

The findings of current study showed that, although higher existential dimension of spiritual well-being contributed to decreased anxiety, higher degree of negative religious coping increased the risk of severe anxiety. Similar observation was evident for risk of severe depression. In fact, the results obtained from this study indicated that patients with lower negative religious coping and higher levels of existential well-being had lower levels of severe anxiety and depression. This might be true for any individual from different religions; however, we think Iranian patients were under the influence of Islamic believes and thus positive thinkers showed better mental health. Islam emphasizes on the strategies to cope with negative life events and reduces stress levels including having positive thoughts, to stay hopeful, consider God's mercy, the remembrance of God and have patience in facing problems..$^{29,30}$ Furthermore, as Muslims believe, Allah is able to do all things: "And never give up hope of Allah's soothing mercy: truly no one despairs of Allah's soothing mercy, except those who have no faith." (Quran, 12:87)31. 
Table 4 The results obtained from multiple logistic regression analysis indicating risk factors for depression $(n=213)$

\begin{tabular}{|c|c|c|c|}
\hline & $O R^{a}$ & $95 \% \mathrm{Cl}$ & $P$ \\
\hline Age (years) & 1.03 & $0.98-1.10$ & 0.188 \\
\hline \multicolumn{4}{|l|}{ Gender } \\
\hline Male & 1.0 (ref.) & & \\
\hline Female & 0.95 & $0.30-3.01$ & 0.932 \\
\hline \multicolumn{4}{|l|}{ Education } \\
\hline Primary & 0.22 & $0.04-1.10$ & 0.066 \\
\hline Secondary & 0.35 & $0.10-1.14$ & 0.083 \\
\hline Higher & 1.0 (ref.) & & \\
\hline \multicolumn{4}{|l|}{ Marital status } \\
\hline Single & 1.0 (ref.) & & \\
\hline Married & 1.80 & $0.51-6.32$ & 0.355 \\
\hline Divorced & 1.43 & $0.25-8.05$ & 0.683 \\
\hline \multicolumn{4}{|l|}{ Employment status } \\
\hline Employed & 1.0 (ref.) & & \\
\hline Unemployed & 0.92 & $0.20-4.25$ & 0.920 \\
\hline \multicolumn{4}{|c|}{ Neurological classification of spinal cord injury (ASIA grade) } \\
\hline Incomplete & 0.79 & $0.32-1.92$ & 0.605 \\
\hline Complete & 1.0 (ref.) & & \\
\hline Time since injury & 0.94 & $0.84-1.05$ & 0.314 \\
\hline \multicolumn{4}{|l|}{ Spirituality well-being } \\
\hline Religious well-being & 1.01 & $0.95-1.08$ & 0.552 \\
\hline Existential well-being & 0.90 & $0.84-0.96$ & 0.001 \\
\hline \multicolumn{4}{|l|}{ Religious coping } \\
\hline Positive religious coping & 0.94 & $0.83-1.07$ & 0.420 \\
\hline Negative religious coping & 1.21 & $1.06-1.37$ & 0.004 \\
\hline
\end{tabular}

Abbreviations: ASIA, American Spinal Injury Association; $\mathrm{Cl}$, confidence interval; OR, odds ratio. adjusted for all independent variables using the enter model.

Several studies from Iran in different samples of patients including patients affected by mustard gas, multiple sclerosis, hemodialysis and cancer confirm our findings. ${ }^{31-34}$ For instance, a qualitative study in patients affected by mustard gas revealed that they were using spirituality to handle stressful conditions they face because of their disease complications. ${ }^{31}$

The findings from the present study indicated that gender was a significant predictor of anxiety. Indeed, women experienced a higher level of perceived anxiety compared with male. Similarly, a study reported that the occurrence of anxiety among women with traumatic SCI was more common than male patients. ${ }^{11}$ In addition, a research has reported that $51 \%$ of women with SCI had anxiety. ${ }^{35}$ This is an important finding, as this might lead to a gender inequality. The findings suggest that there should be more attention to this group of patients and ways should be found to reduce their anxiety.

The findings from this study should be interpreted with caution, as the study had several limitations. The study design was cross-sectional, and we only focused on one coping strategy, whereas there are other forms of coping strategies that do not involve religion and spirituality—such as, participation in a non-religious community, support group, team sport/physical activity or craft.

Finally, as indicated, patients with SCI suffer from multiple challenges that can affect their psychological and physical well-being.
Indeed, there is a need to recognize these challenges and help patients in order to improve their quality of life.

\section{DATA ARCHIVING}

There were no data to deposit.

\section{CONFLICT OF INTEREST}

The authors declare no conflict of interest.

\section{ACKNOWLEDGEMENTS}

We thank all patients who participated in this study.

1 Jazayeri SB, Beygi S, Shokraneh F, Hagen EM, Rahimi-Movaghar V. Incidence of traumatic spinal cord injury worldwide: a systematic review. Eur Spine J 2014; 24: 905-918.

2 Rahimi-Movaghar V, Sayyah MK, Akbari H, Khorramirouz R, Rasouli MR, Moradi-Lakeh $\mathrm{M}$ et al. Epidemiology of traumatic spinal cord injury in developing countries: a systematic review. Neuroepidemiology 2013; 41: 65-85.

3 Rahimi -M, ovaghar V, Saadat S, Rasouli MR, Ganji S, Ghahramani M, Zarei MR et al. Prevalence of spinal cord injury in Tehran, Iran. J Spinal Cord Med 2009; 32: 428-431.

4 Turk MA. Secondary conditions and disability. In:Field MJ, Jette AM, Martin L (eds). Workshop on Disability in America: a New Look. Natl Acad Pr: Washington (DC), USA, 2006, pp 185-193.

5 Harvey L. A Guide for Physiotherapists. Churchill Livingstone: Philadelphia, PA, USA, 2008.

6 Craig A, Tran Y, Middleton J. Psychological morbidity and spinal cord injury: a systematic review. Spinal Cord 2009; 47: 108-114.

7 Hancock KM, Craig AR, Dickson HG, Chang E, Martin J. Anxiety and depression over the first year of spinal cord injury: a longitudinal study. Paraplegia 1993; 31: 349-357.

8 Malec J, Neimeyer R. Psychologic prediction of duration of inpatient spinal cord injuryrehabilitation and performance of self-care. Arch Phys Med Rehabil 1983; 64: 359-363.

9 Elliott TR, Frank RG. Depression following spinal cord injury. Arch Phys Med Rehabi 1996; 77: 816-823.

10 Zimmerman M, Lish JD, Farber NJ, Hartung J, Lush D, Kuzme MA et al. Screening for depression in medical patients. Is the focus too narrow? Gen Hosp Psychiatry 1994; 16: 388-396.

11 Al-Owesie RM, Moussa NM, Robert AA. Anxiety and depression among traumatic spinal cord injured patients. Neurosciences (Riyadh) 2012; 17: 145-150.

12 Harold G. Koenig, religion, spirituality, and medicine: research findings and implications for clinical practice. South Med J 2004; 97: 1194-1200.

13 Johnstone B, Glass BA, Oliver RE. Religion and disability: clinical, research and training considerations for rehabilitation professionals. Disabil Rehabil 2007; 29: 1153-1163.

14 http://en.wikipedia.org/wiki/Religiosity.

15 Cotton S, Puchalski CM, Sherman SN, Mrus JM, Peterman AH, Feinberg J et al. (2006) Spirituality and religion in patients with HIV/AIDS. J Gen Intern Med 2006; 21: S5-S13.

16 Zwingmann C, Klein C, Büssing A. Measuring religiosity/spirituality: theoretical differentiations and categorization of instruments, Religions 2011: 2: 345-357.

17 Muldoon M, King N. Spirituality, health care, and bioethics. J Relig Health 1995; 34: 329-349.

18 Sussman S, Nezami E, Mishra S. On operationalizing spiritual experience for health promotion research and practice. Altern Ther Clin Pract 1997; 4: 120-125.

19 Koenig GH. Religion, spirituality, and medicine: research findings and implications for clinical practice. South Med J 2004; 97: 1194-1200.

20 Maynard FM Jr, Bracken MB, Creasey G, Ditunno JF Jr, Donovan WH, Ducker TB et al. International standards for neurological and functional classification of spinal cord injury. American Spinal Injury Association. Spinal Cord 1997; 35: 266-274.

21 Pargament KI, Koenig HG, Perez LM. The many methods of religious coping development and initial validation of the RCOPE. J Clin Psychol 2000; 56: 519-543.

22 Rohani C, Khanjari S, Abedi HA, Oskouie F, Langius-Eklöf A. Health index, sense of coherence scale, brief religious coping scale, and spiritual perspective scale: psychometric properties. J Adv Nurs 2010; 66: 2796-2806.

23 Paloutzian RF, Ellison CW. Loneliness, spiritual well-being, and quality of life. In: Peplau LA, Perlman D (eds). Loneliness: a Sourcebook of Current Theory, Research and Therapy. Wiley: New York, NY, USA. 1982: 224-237.

24 Baljani E, Khashabi J, Amanpour E, Azimi N. Relationship between spiritual well-being, religion, and hope among patients with cancer. HAYAT 2011; 17: 27-37.

25 Montazeri A, Vahdaninia M, Ebrahimi M, Jarvandi S. The Hospital Anxiety and Depression Scale (HADS): translation and validation study of the Iranian version. Health Qual Life Outcomes 2003; 1: 14.

26 Noorbala AA, Yazdi SB, Yasamy MT, Mohammad K. Mental health survey of the adult population in Iran. Br J Psychiatry 2004; 184: 70-73. 
27 Williams R, Murray A. Prevalence of depression after spinal cord injury: a meta-analysis Arch Phys Med Rehabil 2015; 96: 133-140.

28 Migliorini C, Tonge B, Taleporos G. Spinal cord injury and mental health. Aust $N Z$ Psychiatry 2008; 42: 309-314.

29 Sabry WM, Vohra A. Role of Islam in the management of psychiatric disorders. Indian J Psychiatry 2013; 55: S205-S214.

30 Aflakseir A, Coleman PG. Initial development of the Iranian religious coping scale. J Muslim Ment Health 2011; 6: 44-61.

31 Ebadi A, Ahmadi F, Ghanei M, Kazemnejad A. Spirituality: a key factor in coping among Iranians chronically affected by mustard gas in the disaster of war. Nurs Health Sci 2009; 11: 344-350.
32 Allahbakhshian M, Jaffarpour M, Parvizy S, Haghani H. A Survey on relationship between spiritual wellbeing and quality of life in multiple sclerosis patients. Zahedan J Res Med Sci 2010; 12: 29-33.

33 Kharame ZT, Zamanian H, Foroozanfar S, Afsahi S. Religious wellbeing as a predictor for quality of life in Iranian hemodialysis patients. Glob J of Health Sci 2014; 6 261-269.

34 Haghighi F. Correlation between religious coping and depression in cancer patients. Psychiatr Danub 2013; 25: 236-240.

35 Townsend M, Kladder V, Ayele H, Mulligan T. Systematic review of clinical trials examining the effects of religion on health. South Med J 2002; 95: 1429-34. 